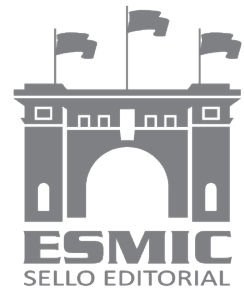

Revista Científica General José María Córdova

ISSN 1900-6586 (impreso), 2500-7645 (en línea)

Volumen 16, Número 23, julio-septiembre 2018, pp. 165-180

http://dx.doi.org/10.21830/19006586.295

Citación: Arango Morales, X. A. (2018, junio-septiembre). Nuevos rumbos legislativos al final de la Guerra Fría: Alemania, República Checa y Rusia. Rev. Cient. Gen. José María Córdova, 16 (23), 165 180. DOI: http://dx.doi.org/10.21830/19006586.295

\title{
Nuevos rumbos legislativos al final de la Guerra Fría: Alemania, República Checa y Rusia
}

Sección: Historia

Artículo de investigación científica y tecnológica

Xóchitl A. Arango Morales*

Universidad Autónoma de Nuevo León, Facultad de Ciencias

Politicas y Relaciones Internacionales

New legislative directions at the end of the cold war:

Germany, Czech Republic, and Russia

Novas direçóes legislativas no final da guerra fria:

Alemanha, República Tcheca e Rússia

Nouvelles orientations législatives à la fin de la guerre froide : L’Allemagne, la République tchèque et la Russie

Recibido: 1 de febrero de 2018 • Aceptado: 14 de junio de 2018

* https://orcid.org/0000-0002-0907-452X - Contacto: xochitl.arangomr@uanl.edu.mx 
Resumen. El presente estudio teórico tiene como objetivo describir y analizar el sistema parlamentario que se estableció al fin de la Guerra Fría en Alemania, República Checa y Rusia, después de la caída del Muro de Berlín. Se considera como punto de arranque el cambio del sistema político, que dio paso a una economía de mercado y a una democracia moderna. También, se analiza la disciplina parlamentaria como un insumo para la gobernabilidad dentro de un nuevo régimen político del poder legislativo. Se abordan conceptos como cohesión, disciplina y unidad para entender la actuación de dicho poder en función del régimen político del momento. Mediante la visualización de la dinámica operativa del sistema parlamentario, se evidencia la tendencia del congreso hacia un esquema democrático. La metodología utilizada es teórica, descriptiva y deductiva.

Palabras clave: Alemania; Guerra Fría; República Checa; Rusia; sistema legislativo.

\begin{abstract}
This theoretical study aims to describe and analyze the parliamentary system established at the end of the Cold War in Germany, the Czech Republic, and Russia, after the fall of the Berlin Wall. The change of the political system was considered the starting point, which gave way to a market economy and a modern democracy. The parliamentary discipline is also analyzed as an input for governance within a new political regime of the legislative power. Concepts such as cohesion, discipline, and unity are addressed to understand the functioning of this power according to the political regime of the moment. The tendency of Congress towards a democratic scheme is evident by observing the operational dynamics of the parliamentary system. The methodology used was theoretical, descriptive, and deductive.
\end{abstract}

Keywords: Cold War; Czech Republic; Germany; legislative system; Russia.

Resumo: Este estudo teórico tem como objetivo descrever e analisar o sistema parlamentarista estabelecido no final da Guerra Fria na Alemanha, República Tcheca e Rússia, após a queda do Muro de Berlim. O ponto de partida é a mudança no sistema político, que deu lugar a uma economia de mercado e a uma democracia moderna. Também, a disciplina parlamentar é analisada como um insumo para a governança dentro de um novo regime político do poder legislativo. Conceitos como coesão, disciplina e unidade são abordados para compreender o desempenho do referido poder de acordo com o regime político do momento. Ao visualizar a dinâmica operacional do sistema parlamentar, a tendência do congresso em direção a um esquema democrático é evidente. A metodologia utilizada é teórica, descritiva e dedutiva.

Palavras-chave: Alemanha; Guerra Fria; Republica Checa; Rússia; sistema legislativo.

Résumé. Cette étude théorique vise à décrire et analyser le système parlementaire mis en place à la fin de la guerre froide en l'Allemagne, la République tchèque et la Russie, après la chute du mur de Berlin. Le point de départ est le changement du système politique, qui a laissé place à une économie de marché et à une démocratie moderne. En outre, la discipline parlementaire est analysée comme un apport à la gouvernance parmi d'un nouveau régime politique du pouvoir législatif. Des concepts tels que la cohésion, la discipline et l'unité sont adressés pour comprendre la performance de ce pouvoir, selon le régime politique du moment. En visualisant la dynamique opérationnelle du système parlementaire, la tendance du congrès vers un schéma démocratique est évidente. La méthodologie utilisée est théorique, descriptive et déductive.

Mots-clés : Guerre froide ; L'Allemagne ; La République tchèque ; La Russie ; système législatif. 


\section{Introducción}

Uno de los grandes cambios establecidos a nivel mundial como consecuencia de la desaparición de la llamada Guerra Fría fue el nuevo rumbo de los sistemas legislativos de los países que estaban constituidos por un sistema político completamente controlado por el Estado (o lo que algunos analistas insisten en llamar "sistemas comunistas"). El cambio estructural de pasar de un sistema político estatista a uno más abierto generó ciertas modificaciones en uno de los sistemas de poder en el Estado, el sistema legislativo, el cual pasa de ser un Congreso un tanto acartonado — sin repercusiones, ni influencia ni autonomía en la toma de decisiones- a ser un Congreso más crítico de los poderes compartidos.

Es en los sistemas parlamentarios en los cuales se puede ver la más amplia representación posible de todo el pueblo, por tanto, la concentración de uno de los poderes permite un reordenamiento de la representación ciudadana en la estructura del sistema de gobierno. Dos de los tres países aquí analizados son parte fundamental del Parlamento Europeo, y se enfrentan, entre otras situaciones, a la falta de un procedimiento auténticamente uniforme para las elecciones parlamentarias europeas. Esto ilustra no solo la dificultad de conciliar diferentes tradiciones nacionales, sino también los procesos de aprendizaje de la política interna de cada implicados por su participación en el Parlamento Europeo.

El objetivo del presente estudio teórico es tener una visión de la situación política de Rusia, Alemania y República Checa, antes de la desaparición de la Guerra Fría, así como conocer y analizar la funcionalidad del sistema parlamentario después del derrumbe del Muro de Berlín. Una variable fundamental en la que se enfoca la presente investigación es la disciplina parlamentaria en calidad de elemento funcional de los sistemas parlamentarios de Estado, la cual es vista por diversos autores —entre ellos, Valencia (2005) — como un insumo para la gobernabilidad parlamentaria.

Es por ello que, en la siguiente propuesta teórica, se hace primero una aproximación a las características del sistema legislativo de los tres países mencionados, los cuales pasaron a ser Estados con un sistema de apertura democrática y de mayor participación política, y llegaron a constituirse incluso en países con grandes elementos de democracia.

Este estudio permite darle a la comunidad académica y ciudadana una primera aproximación al conocimiento del proceso de cambio (dentro de un entorno parlamentario) de un sistema cerrado de Estado que pasa a ser un sistema democrático y de apertura comercial. Con ello, se ofrece un panorama general sobre la transferencia sistémica, lo cual les permitiría a los investigadores generar análisis prospectivos respecto a la tendencia de estos países en el terreno de la democracia parlamentaria. En efecto, reflexionar sobre los cambios del sistema político de los países da la pauta a todo actor de la arena política y a los estudiosos de estos fenómenos para avanzar en la gobernanza parlamentaria y hacer pronósticos en cuanto al comportamiento de las distintas formas de gobierno. 


\section{El orden político de los sistemas comunistas: ¿disciplina parlamentaria?}

El reconocimiento público de que los sistemas políticos del mundo avanzaban con rumbos diferentes hizo llamar la atención sobre los sistemas que se asumían como un régimen comunista. Desde una perspectiva democrática, se planteó si dichos sistemas estaban siendo eficaces de acuerdo con las características que estaba tomando el sistema político internacional. Esa preocupación se hizo tangible con el derrumbe de la Unión Soviética y el término de la Guerra Fría.

En los años posteriores a la Primera Guerra Mundial, el partido oficialista del Imperio alemán ya no estaba en diálogo con el parlamento y parecía que había dado por terminado su diálogo con los partidos liberales, por lo que se iba a adueñar del poder mediante la violencia. Debido a esto, se podía vislumbrar el dominio que ejercía el Estado sobre el sistema parlamentario. De igual forma, de 1948 a 1989, la actual República Checa estuvo dirigida por un gobierno comunista, es decir, el control ejercido por el Estado se hacía presente como sistema apegado al cobijo de la URSS, con la que mantenía un sistema legislativo similar al sistema ruso (Valvidares, 2003)

Pero la gran mole que mantenía el dominio y control del sistema comunista era la URSS, que funcionaba en un marco de un solo partido en el Congreso y permitía, así, la gobernabilidad del Estado. Sin embargo, los cambios en los sistemas políticos con partidos dominantes en los Congresos se estaban dando a pasos agigantados en varios países del mundo, entre ellos, el país que englobaba a un conglomerado de países con sistemas controlados o estatistas, como la República Checa y la Unión Soviética.

Recordemos que uno de los iniciadores de las grandes reformas estructurales del sistema político de la URSS fue Gorbachov, y una de las primeras reformas fue la económica en 1989, a la que llamaban economía socialista de mercado. Este plan habría de concluir en 1995 (Aganbeguián, 1991).

La llegada de Gorbachov al poder fue determinante para el cambio de rumbo que tomaría la URSS. Aquel fue elegido por pertenecer a la llamada "línea blanda", es decir, a aquellos que pugnaban por iniciar reformas económicas y cambios políticos, iniciando con reformas dentro de los límites existentes dentro del sistema, para posteriormente continuar con la reorganización (Perestroika). El propio Gorbachov planteaba que el país necesitaba grandes transformaciones, en las cuales el sistema parlamentario no era la excepción, puesto que necesitaba ser reactivado e integrado con un sistema multipartidista.

Fue a partir de 1990 que inició la lucha por parte de Borís Yeltsin para separar el gobierno del poder central, ya que él fue el primer presidente de Rusia. Yeltsin y sus partidarios nacionalistas moderados decidieron que ese era el momento, por lo que crearon las condiciones para la plena independencia de Rusia, así como para sustituir las antiguas estructuras centralistas gubernamentales soviéticas que imperaban en el viejo régimen (Alvarado, 1992). 
La disolución de la URSS se dio en 1991, para dar paso a la Comunidad de Estados Independientes, los cuales, a partir de 1993 (Alvarado, 1992), crearon una forma de gobierno de la élite reformista rusa, la cual se fragmentó y se embarcó en un proceso de involución ideológica que, en algunos casos, malogró los proyectos democráticos de Rusia.

Si bien el segundo gran reformista de la URSS, Borís Yeltsin, llegó a tener una mayor popularidad que Gorbachov, fue este último el responsable de dar los primeros pasos para desmantelar el sistema comunista, y quien permitió que durante estos periodos la libertad de expresión fuera mayor, así como la libertad para que el poder legislativo pudiera criticar libremente al ejecutivo (lo cual establecía uno de los caminos hacia la democracia).

De hecho, aquel control que ejercía el Estado sobre el sistema legislativo bajo el régimen comunista no se le podía atribuir a la eficiencia funcional de cooperación entre los poderes dominantes, sino al orden ejercido por el control absoluto de un partido que era vinculante con quien se encontraba en el poder. Por lo tanto, la forma en que el trabajo legislativo se ejercía en los sistemas controlados se debía a lo que Weber llamaba el dominio del poder. Al respecto, este autor señalaba: "dominar significa necesariamente poder mandar y ejercitar la coacción para que lo mandado se cumpla, el sometido puede escaparse de cualquier poder, pero no del poder del gobernante" (Weber, 2010, p. 18), es decir, es una caracterización de mando-obediencia. Desde otra perspectiva de análisis, a esta funcionalidad de orden parlamentario se le llama disciplina legislativa.

El tema de la disciplina legislativa es definido como la acción y efecto que rige el cuerpo legislativo de cada partido político en el sistema parlamentario (definición propia con apoyo del Diccionario de la Lengua Española). Este fenómeno tiene una variedad de explicaciones, entre ellas, factores exógenos al Congreso, la predominancia de un solo partido y el poder metaconstitucional del presidente, factores que llevaban, en su conjunto, a determinar cierto comportamiento estructurado de los legisladores. Esto ocurría en los sistemas en los cuales la ausencia de elementos democráticos creaba las condiciones para que los diputados se establecieran en una disciplina legislativa. Para Valencia (2005) la disciplina legislativa es

... percibida como sinónimo de sumisión y condenada por aquellos que se guiaban por la definición clásica del mandato representativo bajo la idea de que el parlamento no debe recibir más instrucciones que las de su propia conciencia. Una vez que hay pluralidad, la connotación de la disciplina cambia, ya que es un mecanismo que permite la simplificación de la coherencia de los grupos parlamentarios (p. 6).

Ahora bien, puede darse una confusión en los términos cohesión y disciplina parlamentaria. El primero, de acuerdo con Valencia (2005), se define como el resultado de lo que mantiene vinculados a los legisladores, como un objetivo en común o intereses comunes. La disciplina parlamentaria, por su parte, se refiere al producto del control que ejercen los líderes de partido sobre los legisladores o miembros de este. Para mayor clari- 
dad, en la tabla 1 se analiza la similitud de conceptos y la diferencia sustantiva entre estos desde la perspectiva legislativa.

Tabla 1. Definiciones y conceptos relacionados con la cohesión y la disciplina

\begin{tabular}{lll}
\hline Concepto & Unidad de análisis & \multicolumn{1}{c}{ Definiciones } \\
\hline Cohesión & $\begin{array}{l}\text { Comportamiento } \\
\text { partidista }\end{array}$ & $\begin{array}{l}\text { Grado de homogeneidad de los miembros de } \\
\text { un partido en el ámbito legislativo (Ruiz y } \\
\text { García, 2001; Sartori, 1994). }\end{array}$ \\
Disciplina & $\begin{array}{l}\text { Comportamiento } \\
\text { individual }\end{array}$ & $\begin{array}{l}\text { Acatamiento de los miembros del partido } \\
\text { (Bowle, Ferrel y Katz, 1999). }\end{array}$ \\
Unidad & $\begin{array}{l}\text { Comportamiento } \\
\text { partidista }\end{array}$ & $\begin{array}{l}\text { Grado de interrelación entre cohesión y disci- } \\
\text { plina (Morgenstern, en prensa). }\end{array}$ \\
Lealtad & $\begin{array}{l}\text { Comportamiento } \\
\text { individual }\end{array}$ & $\begin{array}{l}\text { Frecuencia en el cambio de etiqueta partidista } \\
\text { por parte de los miembros de un partido (Ruiz }\end{array}$ \\
& $\begin{array}{l}\text { y García, 2001). } \\
\text { Ideas compartidas de } \\
\text { Grado de congruencia en las posturas ideoló- } \\
\text { partidos }\end{array}$ & $\begin{array}{l}\text { gicas y programáticas de los miembros de un } \\
\text { partido (Ruiz y García, 2001). }\end{array}$ \\
\hline
\end{tabular}

Fuente: Valencia (2004, p. 16).

Estas definiciones tienen que ver con un grado de aproximación entre los actores políticos, en este caso, los legisladores, que se diferencian por el objetivo que buscan alcanzar. Para el caso de los sistemas con un régimen de Estado, todas las definiciones antes mencionadas eran formas eficaces de control y la productividad legislativa era marcada por el líder que se encontraba en el poder.

Para algunas acciones del gobierno, los términos antes mencionados son favorables, ya que benefician las propuestas del ejecutivo, le dan salida expedita a las leyes y generan una relación de cooperación entre el ejecutivo y el legislativo; sin embargo, esto no significa que sea lo más democrático que deba ocurrir en el sistema parlamentario, por el contrario, son una muestra de que no existe el consenso y de que se está anteponiendo el interés político del ejecutivo sobre el interés del ciudadano.

Estos términos nos llevan a reflexionar que, si el ejecutivo es el líder dominante en un gobierno con un partido que tiene mayoría y, como consecuencia, el dominio en el Congreso, se dará, entre otras cosas, una pobre fiscalización del poder ejecutivo, lo que deja en la opacidad a los procesos de evaluación entre poderes. De acuerdo con estos argumentos, la disciplina parlamentaria en los sistemas comunistas representaba el control y el dominio por parte de quien ejercía el poder. En efecto, la obediencia de los diputados se sometía a una estructura lineal que le permitía al gobernante un amplio margen de ma- 
niobra sin monitoreo, lo cual llegaba a ser solo un sistema parlamentario de simulación. En consecuencia, dadas las circunstancias de influencia del sistema internacional hacia la tendencia de un sistema no solo de apertura comercial sino de política abierta, las formas comunistas de gobierno se encontraban en declive debido al término de la guerra entre las dos potencias.

\section{Orden legislativo posterior a la caída del Muro de Berlín}

Como se mencionó con anterioridad, el fin de la Guerra Fría trajo consigo un sinfín de cambios en los sistemas económicos, políticos, sociales y, por supuesto, en los sistemas legislativos. En el nuevo orden que se estaba dando en Europa Occidental y en Europa Oriental, la restructuración del sistema legislativo vino a replantear la forma de hacer política en los sistemas que antiguamente eran de Estado. Estos temas se tratarán en los siguientes apartados.

\section{Sistema legislativo de Alemania}

El sistema parlamentario de Alemania se introduce tardíamente en comparación con otros países europeos, ya que este se debilitó por la figura del presidente federal. La Alemania de la posguerra establece como forma de organización del Estado un federalismo, es decir, una forma de gobierno de democracia parlamentaria. El sistema parlamentario se integra de la siguiente manera:

- Bundestag (Cámara de Diputados), integrado por al menos 656 miembros, de los cuales 328 son electos en forma directa y 328 (en principio) por fórmula proporcional, utilizando el método Niemeyer, es decir, elecciones libres, universales y secretas, para un periodo de mandato de cuatro años. El Bundestag tiene la responsabilidad de elegir al canciller federal, quien está sujeto a la confianza del parlamento.

- Bundesrat (Cámara de Senadores), integrado por 68 senadores electos de forma directa, quienes ostentan un mandato de cuatro años (González, 2000).

Ahora bien, en el reciente proceso de apertura democrática del sistema parlamentario en Alemania, la falta de cohesión fue inminente — como ha ocurrido con la mayor parte de los sistemas parlamentarios del mundo- En el caso de la nación germana, la situación se fue al extremo, con un sistema de partido fragmentado y con partidos no cohesivos. No obstante, el proceso de madurez que se llegó a concretar en Alemania en el sistema legislativo le ha permitido a esta nación actuar al margen del gobierno en tres aspectos fundamentales: la legislación misma, la fiscalización y la presupuestación.

El proceso de evolución del sistema parlamentario en Alemania llevó a la construcción de un sistema multipartidista, en el que hoy en día funcionan cinco partidos. Lo 
anterior nos lleva a concluir que el sistema legislativo posdeclive del Muro de Berlín fue un poder constituido de ideologías y formas de representación democrática, enmarcadas en la arena política de la negociación, pero con esquemas altamente democráticos y defensores de la ciudadanía. El procedimiento legislativo se describe a continuación:

El procedimiento legislativo otorga absoluta primacía al Bundestag siendo tanto el Bundesrat como el gobierno instancias complementarias y de apoyo de aquella, el Bundesrat aporta experiencia administrativa, el gobierno brinda conocimiento específico de las materias. Cierra el ciclo el presidente federal, a quien le corresponde la sanción de las leyes. Pero queda claro que la competencia legislativa es un monopolio del Bundestag. (Monedero, s. f., p. 39)

El Parlamento alemán ha permitido tener representación de partidos minoritarios, que se han movido en coalición desde 1949. De esta forma, para evitar que el Parlamento se fragmente, los partidos deben obtener como mínimo un porcentaje del $5 \%$ de los votos emitidos, con lo cual tienen representación en el Bundestag. Esto aparece planteado en La actualidad de Alemania (Bischoff, Chauvistré, Kleis, \& Wille, 2015) como se describe a continuación:

Desde las elecciones al 18 Bundestag alemán (2013), el país es gobernado por una coalición entre la CDU/CSU y el SPD, popularmente conocida como Gran Coalición, porque reúne a las dos principales fuerzas del sistema de partidos alemán. De los 630 escaños del Bundestag, 503 corresponden a los diputados de la coalición de gobierno (CDU/CSU 310, SPD 193). La oposición parlamentaria, formada por La Izquierda (64 diputados) y Alianza 90/Los Verdes (63 diputados), solo suma 127 escańos, la cifra más baja desde hace más de 40 años. (p. 26)

\section{Sistema legislativo de la República Checa}

En la República Checa se dio un sistema de apertura en el marco de lo que se denominó "Revolución de Terciopelo". En 1989 el régimen fue derribado y la antiguamente nombrada Checoslovaquia se convirtió en un país democrático debido a su naturaleza pacífica, lo que llevó a que en 1990 se celebraran las primeras elecciones libres. No obstante, en enero de 1993, Checoslovaquia se separó en dos Estados independientes: República Checa y Eslovaquia. (Casanova, 1997), de acuerdo con la Constitución promulgada en 1992.

La integración de poder legislativo se estructuró, en la República Checa, en un Parlamento bicameral, compuesto por la Cámara de Diputados (denominada Consejo Nacional e integrada por 200 miembros) y la Cámara de Senadores (integrada por 81 representantes de circunscripciones electorales) cuyos integrantes son elegidos por mayoría relativa a dos vueltas, por cuatro y seis años respectivamente. Es responsabilidad del Parlamento, entre otras actividades, la elección del presidente, la elaboración y aprobación de leyes, y las manifestación o denegación de la confianza en el Gobierno. La República 
Checa logró cumplir con uno de los objetivos más importantes: crear un sistema político de partidos que funcionara en una democracia parlamentaria pluralista (Gómez, 2012).

El sistema legislativo de República Checa se encarga de aprobar los acuerdos internacionales o bien algunas modificaciones a la Constitución, mediante votación por más de la mitad de ambas cámaras. Puesto que este sistema también discute y aprueba leyes, el Estado Checo es una representación democrática parlamentaria, conforme a la división y a las tareas de cada poder (ejecutivo, legislativo o bien judicial).

Es pertinente mencionar que el avance en materia de profesionalización que se ha experimentado en este país ha sido fundamental para la consolidación del trabajo legislativo. A principios de los noventa, el Comité de Presupuesto y el Parlamento en conjunto, estaba compuesto por personas sin experiencia en política de alto nivel, y solo rara vez tenían un diputado con experiencia económica. De manera conjunta, se acordó que los nombramientos para el Comité tuviesen en cuenta el antecedente profesional, con lo cual se llegó a que los diputados fueran más profesionales y críticos con el trabajo (Stapenhurst, Pelizzo, Olson, \& Trapp, 2009).

La profesionalización antes mencionada se muestra como un proceso de transformación y de consolidación democrática, ya que a principios de los noventa el Comité de presupuesto estaba integrado por legisladores sin experiencia. Fue en la primera reunión del Comité que se acordó que se tuviera en cuenta el antecedente profesional, propuesta que fue rechazada. Sin embargo, paulatinamente los diputados han sido más profesionales y han aprendido a obtener información y evaluar críticamente; hoy en día es el Comité más prestigioso del Parlamento (Stapenhurst, Pelizzo, Olson, \& Trapp, 2009).

La participación de la República Checa en el Parlamento de la Unión Europea ha logrado conquistar 24 escaños. Después de un arduo trabajo de modificaciones sistemáticas que tuvo que llevar a cabo el país, la República Checa formó parte de la Unión Europea en mayo del 2004. Al igual que Alemania, la República Checa ha adquirido un grado de madurez que le ha permitido actuar al margen del Gobierno en tres aspectos: la legislación, la fiscalización y la presupuestación. Posterior a la caída del Muro de Berlín, junto a los países que tenían sistemas comunistas, la República Checa es, al lado de Polonia, la que ha alcanzado grandes efectos de democratización. Finalmente, la República Checa, al igual que la Alemania de posguerra Fría, constituyó su sistema legislativo como un sistema democrático y con grandes tintes de desarrollo hacia la eficacia del trabajo legislativo.

\section{Sistema legislativo en Rusia}

El sistema parlamentario ruso se compone de dos cámaras: la llamada Duma, es decir, la Cámara baja parlamentaria y la Cámara alta (la cual se nombra como el Consejo de la Federación). Desde 1993, la Duma se compone de 450 miembros elegidos por vía electoral cada cuatro ańos. De acuerdo con De Andrés y Ruiz (2008), el Consejo de la Federación y la Duma de Estado forman comités y comisiones y celebran audiencias 
parlamentarias sobre las cuestiones que les incumben. Los miembros del Consejo y de la Duma gozan de inmunidad durante todo el plazo de su mandato.

La influencia que puede tener la Duma dentro del sistema político es determinante, ya que puede aprobar legislaciones, iniciar comisiones para investigaciones, generar resoluciones legislativas y financiación extrapresupuestaria. Cabe aclarar que, a pesar de que puede tener poder en la creación de leyes, este poder es neutralizado por el ejecutivo.

Fue en 1993, cuando Borís Yeltsin publicó el Decreto 1.400, en el que disolvía los parlamentos. El Sóviet Supremo, como el Congreso de Diputados Populares, se apropiaba del poder legislativo, al mismo tiempo que mandaba a elecciones y convocaba un referéndum sobre la nueva Constitución — cuyo borrador realmente no conocían los ciudadanos ni la clase política del país, lo cual violaba el artículo 121.6 de la Constitución rusa y estaba, por tanto, fuera de la ley-. De acuerdo con Yeltsin, "se justificaban elecciones porque la Federación Rusa era un país nuevo, que vino a ocupar el lugar de la antigua República Federal Soviética de Rusia” (Sáenz, 2003, p. 3).

Posterior a la acción golpista, el Parlamento se reúne de manera urgente con el objetivo de destituir al presidente Yeltsin por violación a la norma constitucional. Después de una serie de disturbios, el presidente manda a elecciones del Parlamento. En general, el Parlamento estaba dividido en ultraliberales y ultranacionalistas. Los primeros comulgaban con los ideales de Yeltsin, pero los ultranacionalistas estaban ligados a la extrema derecha, a los estalinistas que defendían la antigua URSS, pero también de manera intermedia existía un grupo centrista crítico de lo que estaba pasando, un tanto más nacionalista y opuesto al presidente.

Después de 1993, el presidente de Rusia Boris Yeltsin, llevó a cabo la modificación a la Constitución, en la cual el sistema de gobierno era semipresidencialista. Esto, como bien aseveran De Andrés y Ruiz (2008), le daba al gobierno la capacidad de ejercer en solitario, es decir, "se trata de una presidencia hegemónica libre de controles debido al dominio de la formación y control del gobierno, desplazando al Parlamento de un rol efectivo en ambas tareas, de gobernar de manera aislada”. Así, el presidente mantenía la acumulación de ambas competencias legislativas, como el poder de veto y la capacidad de legislar por decreto, así como la prerrogativa sin restricciones para cesar el gobierno y disolver la Duma Estatal (De Andrés \& Ruiz, 2008, p. 4).

Como se ha estado analizando, las legislaturas posautoritarias en las regiones comunistas se han ido desarrollando como sistemas políticos diferentes a partir del colapso del sistema en 1989. La Unión Soviética ingresó a un régimen presidencial: Stapenhurst et al. (2009, p. 192) nos dicen que "el desarrollo de parlamentos activos y autónomos varía de acuerdo con las circunstancias y también la capacidad de los parlamentos de fiscalizar la conducta del gobierno".

Los cambios generados por el nuevo sistema económico permitieron grandes subastas fiduciarias (préstamos por acciones) y ventas de empresas del Estado, por cierto, a costos muy bajos. Debido a estos cambios estructurales en el periodo de 1995 a 2000, 
la Audit Chamber realizó alrededor de 3.000 investigaciones a causa de la gran burocracia que imperaba. De acuerdo con Remington (2013), los informes no tuvieron ningún efecto, aun cuando estos eran anunciados en la prensa. Por ello, la Cámara ha estado en conflicto tanto con el Gobierno como con el ministro de Finanzas, específicamente, por el derecho a efectuar auditorías: "la Cámara no tiene poder de hacer cargos legales y sus informes solo tienen fuerza de asesoría, pero su poder de exponer abusos y corrupción incide en la capacidad del parlamento" (Remington, 2013, p. 187).

Uno de los periodos de controversia parlamentaria, previo a la entrada del presidente Putin, estuvo representado por la dificultad en la creación de coaliciones. También se generó un sistema fragmentado y flotante: "el número de partidos en el legislativo en Rusia ha variado sustancialmente dentro y entre ambos parlamentos. La combinación de un sistema legislativo que produce un gran número de puntos de veto con mecanismos en el sistema de partidos débiles para organizar coaliciones mayoritarias ha hecho al proceso legislativo ruso vulnerable a las influencias de intereses extraparlamentarios" (De Andrés \& Ruiz, 2008 p. 26). Lo anterior establece que la presión al legislativo, emergida en los años noventa, tuvo efectos políticos típicos de los sistemas presidenciales.

Ahora bien, durante los noventa, un problema recurrente en la Duma fue la influencia de los grupos de presión, quienes defendían a los particulares en áreas como energía, extracción de metales, producción de bebidas alcohólicas y la industria tabacalera, sectores que apoyaron el crecimiento en la productividad. Es bien sabido que el éxito que obtuvo Putin en el poder legislativo fue mayor al de Yeltsin:

El presidente pasó a controlar dos tercios del parlamento, aquellos que le permitirían cualquier cambio legislativo, y por otro lado destacó paralelamente a la pérdida de peso de fuerzas intrarregionalistas o regionales; se puede concluir que durante el primer mandato de Putin hubo una gran disonancia entre las reformas institucionales, que introdujeron algunas mejoras reales en el sistema de partido y la práctica de política de la manipulación electoral, la cual aseguró resultados favorables al Kremlin. (de Andrés \& Ruiz, 2008)

De manera conjunta, el ejecutivo y el Parlamento terminaron desencadenando una serie de consecuencias no previstas. Querían la reforma del sistema y terminaron transitando al capitalismo, querían modernizar la estructura política, ampliando la participación ciudadana, y terminaron polarizando a la sociedad y liberando fuerzas centrifugas portadoras de otras finalidades que destruyeron la organización partidaria y estatal. Deseaban recomponer los vínculos con las minorías nacionales y terminaron con la URSS disuelta. Intentaron una nueva forma de vincularse con el mundo para reducir la tensión y racionalizar los vínculos externos y terminaron perdiendo el control de las situaciones y los atributos que elevaban a la URSS al rango de superpotencia. (Guerrero, J. C., s. f., p. 10)

Todo lo anterior generó una serie de cambios y nuevas formas de cabildear para estructurar la composición del Parlamento. Al respecto, el 18 de septiembre de 2016 tuvieron lugar las últimas elecciones de la Duma Estatal —en las que participó un 47,9 
$\%$ del censo electoral (la participación en 2011 fue de un 60,1\%) y fueron objeto de observación electoral por parte de OSCE-ODHIR—, las cuales arrojaron los siguientes resultados, de acuerdo con la Oficina de Información Diplomática (2007, p. 6):

- Rusia Unida: 343 diputados, 76,2 \% de los escaños (resultado elecciones 2011: 238 diputados).

- Partido Comunista de la Federación Rusa: 42 diputados, 9,3 \% (resultados elecciones 2011: 92 diputados).

- Partido Liberal Democrático de Rusia (PLDR): 39 diputados, 8,7 \% (resultados elecciones 2011: 56 diputados).

- Rusia Justa: 23 diputados, 5,1\% (resultados elecciones 2011: 64 diputados).

- Partido Rodina ("Patria"): 1 diputado (en 2011 no obtuvo ninguno).

- Plataforma Cívica: 1 diputado (en 2011 el partido no se presentó a las elecciones).

- Diputados no afiliados a ningún partido: 1 (Vladislav Reznik).

- Vacante: 1.

El resto de partidos no superaron el umbral mínimo del $5 \%$ para entrar en la Cámara, ni vencieron en ninguna de las circunscripciones uninominales. Es de destacar que dichas elecciones se desarrollaron de manera pacífica, en un ambiente ordenado y sin manifestaciones ni protestas.

\section{Similitudes en los sistemas legislativos después de la caída del Muro de Berlín}

Una de las grandes tareas de los parlamentos que salían de un sistema comunista a un sistema democratizado era crear comités temporales para tratar de sacar las tareas inmediatas que el sistema con economía abierta demandaba. Estos comités, de acuerdo con Stapenhurst et al. (2009), se utilizaban para atender a problemas nuevos, entre ellos, preparar todo lo relativo al acceso a la Unión Europea y a la Organización de Tratado del Atlántico Norte.

En las democracias poscomunistas, según lo menciona el estudio del Banco Mundial:

Ha predominado una alta rotación de integrantes parlamentarios de una elección a la siguiente en los primeros periodos. Sin embargo, la mayoría de los integrantes de los parlamentos nuevos son nuevos en cada periodo, trayendo con ellos una amplia variedad de experiencia y actitudes. (Stapenhurst et al., 2009, p. 196)

Recordemos que una vez que el sistema político empieza a sufrir transformaciones hacia un proceso más democrático (figura 1), la disciplina deja de ser una constante del sistema, por lo que esta se convierte en un elemento importante de análisis. De acuerdo con Valencia (2005, p. 5), se da la "posibilidad de un escenario de parálisis e ingober- 
nabilidad que impediría el funcionamiento de la asamblea legislativa en un contexto de gobierno dividido en situación de mayoría”.

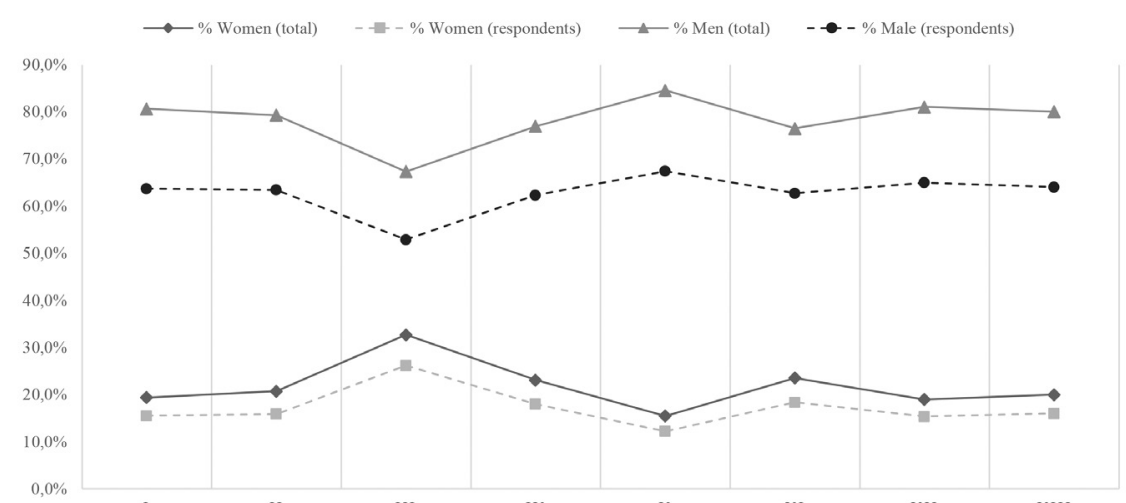

Figura 1. Evolución del control de los sistemas parlamentarios.

Fuente: elaboración propia.

Un factor que influyó de manera decisiva en el desarrollo de su sistema legislativo, especialmente para Alemania y la República Checa, fue la pertenencia a la Unión Europea. Aún en tiempos diferenciados, tal pertenencia les ha permitido alcanzar estándares que llevan a los legisladores a un proceso de desarrollo y régimen mayor que los países del resto del mundo. Por mencionar un ejemplo, está el "código de ética" que tienen los países integrantes de la Unión Europea, bajo cuya norma se limita la conducta del legislador de llevar a cabo prácticas deshonestas que afecten la interrelación con los ciudadanos.

Esto ha permitido que el trabajo legislativo se lleve a cabo en un marco de transparencia y rendición de cuentas, que ha marcado la diferencia con aquellos países que no cuentan con un código de conducta ni comisiones de sanciones para castigar a sus legisladores (por lo cual los niveles de descrédito por parte de la ciudadanía se han posicionado en los más bajos).

\section{Reflexiones finales}

La adopción del régimen parlamentario democrático tuvo como consecuencia, si no la de cambiar su carácter, sí al menos la de corregir — y aun modificar - algunos de los rasgos del régimen anterior. Los tres países anteriormente descritos pasaron por un sistema de Estado controlador, en el cual los poderes representados por el Gobierno estaban unificados con el sistema parlamentario y el poder legislativo representaba los intereses del mismo Gobierno que en ese momento se encontraba en el poder.

A medida que se derrumbó el Muro de Berlín, el sistema comunista abanderado por la URSS inicia su declive, lo que conlleva a que dicho efecto impactara a los países que 
compartían un sistema estatista. Por esta razón, el cambio de un sistema planificado a una economía de mercado, aun cuando fue paulatino, expuso al país a una serie de cambios riesgosos pero necesarios para su evolución. Según Remington (2013, p. 194), "el Estado debilitado que experimenta la democratización durante un tiempo de crisis económica es particularmente vulnerable a la captura y la corrupción por parte de intereses poderosos que buscan beneficios particulares concentrados a expensas del público". En ausencia de instituciones fuertes, abrir el sistema a elecciones competitivas conlleva a problemas de autoridad fragmentada y, fundamentalmente, a un aparato parlamentario con baja producción legislativa. Este periodo lleva a que el sistema político mantenga un sistema de inestabilidad momentánea para poder dar el paso a un sistema de forma democrática.

Lo anterior evidencia que, hoy en día, el sistema parlamentario trabaja por legislación y no por decreto. Por mencionar un ejemplo, la legislación en el periodo del presidente Putin aumentó en forma significativa el control presupuestal y redujo el nivel de evasivas, concesiones y garantías de poder irresponsable en la política fiscal.

En la medida en que los sistemas parlamentarios de países como Rusia, Alemania y la República Checa evolucionaron hacia sistemas democráticos, los congresos se constituyeron por un número heterogéneo de partidos con diferentes ideologías, lo que lleva a preguntarse cómo dichos congresos logran la cooperación. Por esta razón, la disciplina parlamentaria durante el sistema comunista coadyuvó al acatamiento de los miembros de un partido a la influencia de su líder. Para Valencia (2005), esto limita y motiva el comportamiento estratégico de los diputados, cuyo control determina los juegos políticos del poder.

Con el cambio generado por dejar de ser un sistema de gobierno completamente controlado por el Estado y pasar a tener más libertad económica y democrática, los sistemas parlamentarios de estos países iniciaron una nueva dinámica de cabildeo, en la cual los partidos buscan posicionarse para tener el control del Congreso. A pesar de esta dinámica, para el Parlamento de Alemania adentrarse en la justicia transicional, entre otras avenencias, ha generado un proceso de aprendizaje como mediador al que aún no se le saca provecho. Esto es debido a la distancia que generaron entre el Gobierno y la ciudadanía, causada por las viejas ideas de predominio del ejecutivo sobre el legislativo. Sin embargo, el parlamentarismo de la República Federal Alemana es un gran ejemplo de cambio de tendencia de la nación hacia un Estado más democrático.

Respecto a la Federación Rusa, se menciona un factor a favor: la centralización del control político, que ha eliminado puntos de acceso para corporaciones y grupos de presión en torno a aspectos negativos, como el crecimiento exacerbado de cabildeo que se ha dado en los otros países después de la Guerra Fría (De Andrés y Ruiz, 2008).

En relación con la República Checa, el Parlamento se ha idealizado y polarizado de tal manera que ello ha representado un obstáculo para las acciones parlamentarias. Inclusive, se generó un fragmentación de los partidos considerados tradicionalmente de derecha y se dio una nueva agenda para la inserción de una democracia directa y un cambio al statu quo, según lo describe el documento Monitor Electoral (México, Senado de la República, 2017). 
Los cambios que han experimentado los sistemas políticos de Rusia, Alemania y la República Checa les han permitido generar un sistema más independiente del poder ejecutivo, a partir de la generación de un sistema de partidos. Esto ha ocurrido así con la ligera excepción de Rusia, donde el ejecutivo aún mantiene un dominio sobre la Duma rusa. Como se ha visto a lo largo de la descripción del sistema parlamentario de los tres países, la inserción de un sistema político abierto al mercado y democrático ha permitido la reacomodación de la estructura de dichos parlamentos y el ingreso a una nueva dinámica de interacción que no tenían en el régimen anterior a la Guerra Fría, que era controlado completamente por el Estado.

\section{Agradecimientos}

La autora agradece a la Universidad Autónoma de Nuevo León por su apoyo en la realización de este artículo.

\section{Declaración de divulgación}

La autora no declara ningún potencial conflicto de interés relacionado con el artículo.

\section{Financiamiento}

La autora no declara fuente de financiamiento para la realización del artículo.

\section{Sobre la autora}

Xóchitl A. Arango Morales. Profesora de tiempo completo por la Facultad de Ciencias Políticas y Administración Pública de la Universidad Autónoma de Nuevo León, reconocida con el Perfil PROMEP, sus líneas de investigación son Ética pública y legislativa, y Nueva Gestión Pública.

\section{Referencias}

Aganbeguián, A. (1991). La reforma económica en la Unión Soviética. El Socialismo del Futuro, 3, 25-35. Alvarado, E. (1992). La formación del sistema político de la República Rusa. Revista de Estudios Públicos, 95, 125-176.

Bischoff, M., Chauvistré, E., Kleis, C., \& Wille, J. (2015). La actualidad de Alemania. Recuperado de https://www.tatsachen-ueber-deutschland.de/es/system/files/download/tatsachen_2015_spa.pdf.

Casanova, M. (1997). La Revolución de Terciopelo y el movimiento intelectual checoslovaco. Espacio, tiempo y forma. Recuperado de: file://C:/Users/FACPYAP/Downloads/2929-6217-1-PB.pdf.

Chile, Congreso Nacional de Chile. Historia de la Ley N. ${ }^{\circ}$ 17.284, Modifica la Constitución Política del Estado (s. f.).

De Andrés, J., \& Ruiz, R. (2008). Y Putin encontró el camino. Instituciones y régimen político en la Rusia del siglo XXI. UNISCI Discussion Papers, 17, 11-53 
Gómez, J. A., (Coord.). (2012) La ampliación de la Unión Europea de 2004-2007: Pasado, Presente y Futuro. Lublin, Polonia: Wydawnictwo Polihymnia.

González, C. J. (2000). El sistema parlamentario en cinco paises de Europa. Recuperado de http://www. diputados.gob.mx/bibliot/publica/inveyana/polint/cua12/indice.htm.

Guerrero, J. C. (s. f.). Rusia: ¿de potencia mundial a potencia regional? Recuperado de: http://www.uma.es/ foroparalapazenelmediterraneo/wp-content/uploads/2014/04/140426-Oasis_Guerrero_Rusia.pdf.

México, Senado de la República. (2017). Monitor Electoral. Recuperado de http://centrogilbertobosques. senado.gob.mx/docs/ME_RepCheca2017_300117.pdf.

Monedero, J. C. (s. f.) Sistema politico de la República Federal de Alemania. Recuperado de http:// www.juancarlosmonedero.org/wp-content/uploads/2013/07/Sistema-Pol\%C3\%ADtico-de-laRep\%C3\%BAblica-Federal-de-Alemania.pdf.

Oficina de Información Diplomática. (2007). Rusia, Federación de Rusia. Recuperado de: file://C:/Users/ FACPYAP/Downloads/rusia_ficha\%20pais.pdf.

Remington, T. F. (2013). Separación de poderes y fiscalización legislativa en Rusia. Estudio del Instituto del BM sobre desarrollo, fiscalización legislativa y Presupuesto en Rusia. Recuperado de www.wds.worldbank.org.

Sáenz, J. (2003). Los orígenes del sistema político ruso: el autogolpe presidencial de 1993. Papeles del Este, 7, 2-31.

Stapenhurst, R., Pelizzo, R., Olson, D. M., \& Trapp, L. V. (2009). Fiscalización legislativa y presupuestos, una perspectiva mundial. Recuperado de: http://econ.worldbank.org.

Valencia, E. L. (2004). La pluralidad política y su impacto en la disciplina parlamentaria. Sociología, $19(56), 13-52$.

Valencia, E. L. (2005). La disciplina parlamentaria en México. México, D. F.: UNAM.

Valvidares, S. M. (2003). Breve aproximación a la constitución de la República Checa. Revista Española de Derecho Constitucional, 23(67), 233-245.

Weber, M. (2010). Sociología del poder, los tipos de dominación (Joaquín Abellán, Trad.). Madrid: Alianza Editores. 